\title{
Intraoperative loss of surgical needle with 8-0 nylon: radiographic findings
}

\author{
Taro Yanagawa, Yoichi Harada, Keiichi Yamashita, Toru Hatayama
}

Department of Neurosurgery, Mito Brain Heart Center, Mito, Japan

\section{Correspondence to} Dr Taro Yanagawa, smile_880@yahoo.co.jp

Accepted 20 November 2018

\section{DESCRIPTION}

Losing surgical needles during surgery is rare and there are no clear guidelines for managing such a loss. Although it is considered ideal to search until a lost needle is found, the operation usually proceeds at the discretion of the operating surgeon. The small needles $(\leq 5) \mathrm{mm}$ sometimes used during brain surgery are very difficult to locate (eg, needles that are used for 8-0, 9-0 and 10-0 nylon) once lost. A study of radiographic findings of lost surgical needles of various sizes found that the smallest that was detectable by most observers was $17 \mathrm{~mm}{ }^{1}$

Medina et al stated that it is important to implement preventive measures against losing needles and that appropriate and clear communication between team members is important. ${ }^{2}$

The protocol in our hospital is that surgical needles must be stabbed into a sponge before moving the needle and sponge from the surgical field to the instrument tray. However, compliance with this protocol did not prevent loss of a needle in the present case.

We, here, present loss of a $4 \mathrm{~mm}$ stainless steel surgical needle with $8-0$ nylon in a 68-year-old woman during a trapping with high-flow bypass procedure for subarachnoid haemorrhage caused by internal carotid artery dissection. When a needle count revealed that a needle had been lost, the procedure was stopped while all the staff

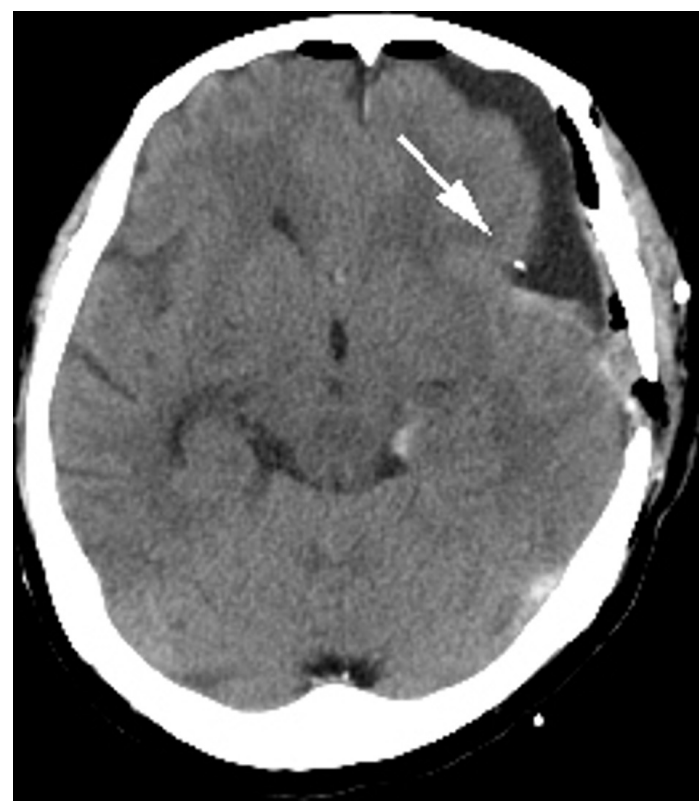

Figure 1 A surgical needle (arrow) was seen on noncontrast CT.

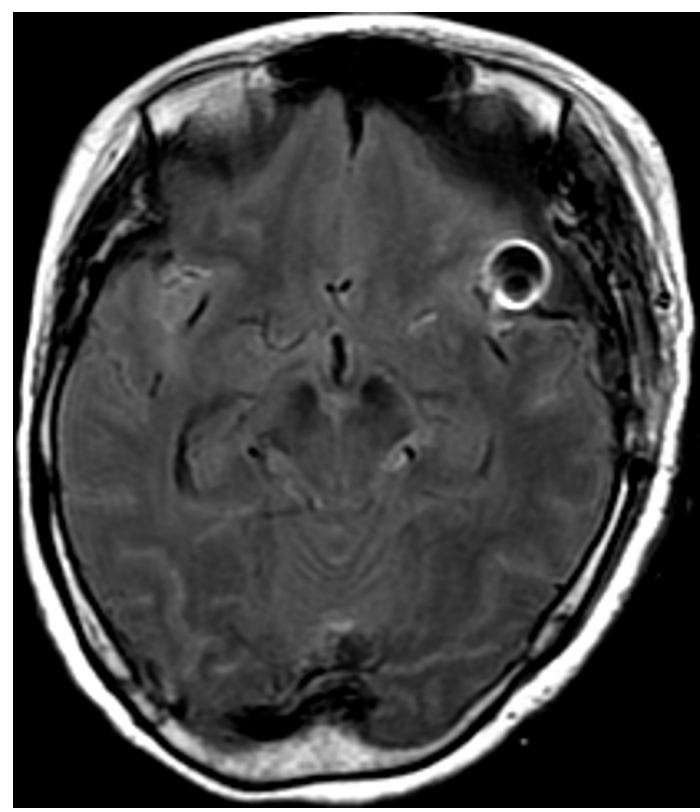

Figure 2 A metal artefact was seen on MRI.

searched the surroundings. Additionally, the video of the procedure was played to determine when the needle had been lost. Despite these measures, the lost needle was not located.

In retrospect, non-contrast CT performed immediately after surgery showed the needle; however, it was not detected at the time (figure 1). It was concluded that it was unlikely that it was still in the patient's head. MRI performed 1-day

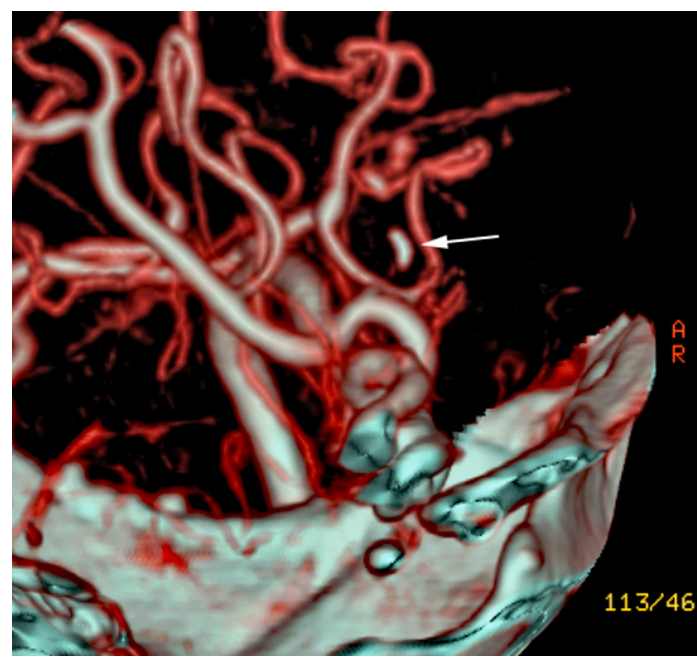

Figure 3 The contrast-enhanced CT image on volume rendering showed the positional relationship between the surgical needle (arrow) and the surrounding tissue. 


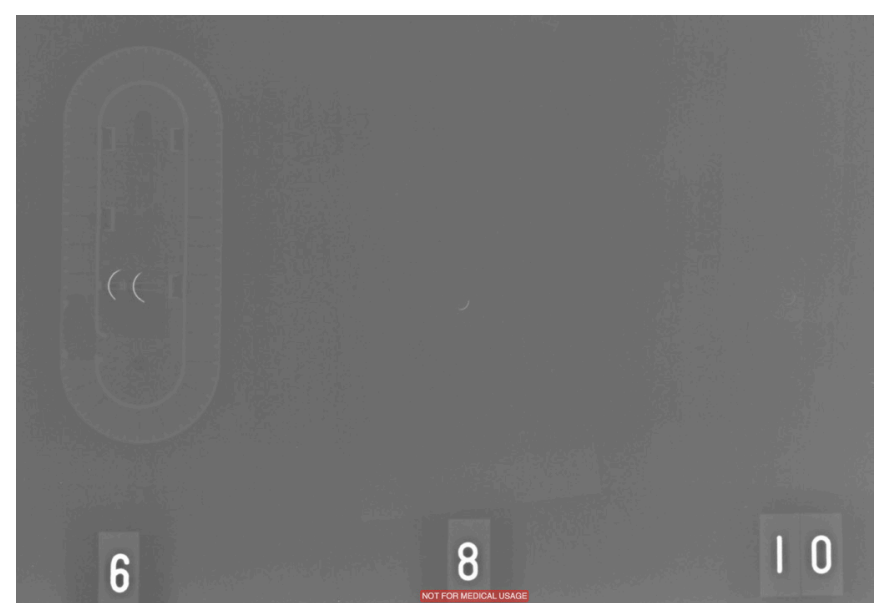

Figure 4 Surgical needles with $6-0,8-0$ and $10-0$ nylon were taken on plain radiography.

postoperatively clearly showed a metal artefact (figure 2). In retrospect, taking a three-dimensional CT before performing an MRI would have been preferable. However, we considered it unlikely that the needle had moved as a result of the MRI examination. Furthermore, we were able to more accurately determine the location of the needle with contrast-enhanced CT (figure 3). After thoroughly explaining the situation to the patient and her family and obtaining consent, we reoperated and successfully removed the needle.

It is difficult to identify surgical needles with $10-0$ nylon in a plain radiograph, whereas those with 6-0 nylon are clearly detectable (figure 4).

Sharma et al have reported that C-arm is more useful for detecting lost needles than a mobile X-ray machine. ${ }^{3}$
Unfortunately, the operation room in our hospital is not equipped with a C-arm or CT facility.

A three-dimensional CT is able to reveal surgical needles with $10-0$ nylon and is therefore recommended for detecting surgical needles with $8-0$ or $10-0$ nylon that have not been found intraoperatively. Contrast-enhanced CT should be performed when planning their removal because it enables determination of the relationships between the needle and adjacent anatomical structures.

\section{Learning points}

- When surgical needles of $<5 \mathrm{~mm}$ are lost during a surgical procedure, discovery of the lost needles could be very difficult.

- Establishment of a protocol for preventing loss of needles and a strategy for managing recovery of lost needles is important.

- Three-dimensional CT is useful for locating lost needles.

Contributors TY: the planning, conduct and reporting. YH: the planning. KY: the conduct. TH: the planning.

Funding The authors have not declared a specific grant for this research from any funding agency in the public, commercial or not-for-profit sectors.

Competing interests None declared.

Patient consent for publication Obtained.

Provenance and peer review Not commissioned; externally peer reviewed.

\section{REFERENCES}

1 Macilquham MD, Riley RG, Grossberg P. Identifying lost surgical needles using radiographic techniques. Aorn J 2003;78:73-8.

2 Medina LG, Martin 0, Cacciamani GE, et al. Needle lost in minimally invasive surgery: management proposal and literature review. J Robot Surg 2018;12:391-5.

3 Sharma AP, Mete UK, Bendapuddi D, et al. Needle in a haystack: lost in transition. J Robot Surg 2018;12:177-9.

Copyright 2018 BMJ Publishing Group. All rights reserved. For permission to reuse any of this content visit https://www.bmj.com/company/products-services/rights-and-licensing/permissions/

BMJ Case Report Fellows may re-use this article for personal use and teaching without any further permission.

Become a Fellow of BMJ Case Reports today and you can:

- Submit as many cases as you like

- Enjoy fast sympathetic peer review and rapid publication of accepted articles

- Access all the published articles

Re-use any of the published material for personal use and teaching without further permission

For information on Institutional Fellowships contact consortiasales@bmjgroup.com

Visit casereports.bmj.com for more articles like this and to become a Fellow 